\title{
Modelling Studies on Reactive Absorption of Carbon Dioxide in Monoethanolamine Solution from Flue Gas in Coal Based Thermal Power Plants
}

\author{
Tanmay Singhal, Sampatrao D. Manjare ${ }^{* 2}$ \\ ${ }^{1}$ Department of Chemical Engineering, BITS Pilani K K Birla Goa Campus, NH 17B, Bypass Road, \\ Zuarinagar, Sancoale, Goa 403726, India \\ e-mail: singhal.tanmay.2013@gmail.com \\ ${ }^{2}$ Department of Chemical Engineering, BITS Pilani K K Birla Goa Campus, NH 17B, Bypass Road, \\ Zuarinagar, Sancoale, Goa 403726, India \\ e-mail: manjare@goa.bits-pilani.ac.in
}

Cite as: Singhal, T., Manjare, S. D., Modelling Studies on Reactive Absorption of Carbon Dioxide in Monoethanolamine Solution from Flue Gas in Coal Based Thermal Power Plants, J. sustain. dev. energy water environ. syst., 6(3), pp 481-493, 2018, DOI: https://doi.org/10.13044/j.sdewes.d6.0227

\begin{abstract}
In this paper the detailed theoretical investigation on absorption of carbon dioxide, from flue gas in coal based thermal power plants has been presented. For absorption studies, monoethanolamine solution is considered as a solvent. The mathematical model for the absorption column has been developed by considering thin film model approach. Unified method is used for an overall estimation of carbon dioxide absorption. The carbon dioxide concentration profile at a given stage, using the thin film layer model, has been predicted at $298 \mathrm{~K}$ and $318 \mathrm{~K}$. From the results it is noted that carbon dioxide concentration decreases from interface concentration at equilibrium to a minimum of $0 \mathrm{kmol} / \mathrm{m}^{3}$ up to a distance of \pm 2 micrometers. Overall estimation of carbon dioxide absorption has been carried out using the unified model approach. The total amount of carbon dioxide absorbed in absorption column is estimated to be $95.60 \%$ of the inlet carbon dioxide with 30 trays, $L / G$ ratio of 8.5 and carbon dioxide flow rate of $95.74 \mathrm{kmol} / \mathrm{m}^{3}$. The results revealed that reactive absorption is very effective in absorbing carbon dioxide into monoethanolamine solvent.
\end{abstract}

\section{KEYWORDS}

Carbon dioxide absorption, Mass transfer, Henry's law, Film theory, Monoethanolamine.

\section{INTRODUCTION}

India is amongst the top four Carbon dioxide $\left(\mathrm{CO}_{2}\right)$ producing countries with China, US, and countries under European Union, it produced about 2,341,000 kt of $\mathrm{CO}_{2}$ in 2014 [1]. In India, 38\% of total $\mathrm{CO}_{2}$ emission is due to electricity production [2]. $71 \%$ of the total electricity supplied in India is generated using thermal power plant of which $62 \%$ is fulfilled using coal based thermal power plants [3]. This number is huge because India requires a large amount of electricity which is produced by power plants present across the country.

\footnotetext{
${ }^{*}$ Corresponding author
} 
The $\mathrm{CO}_{2}$ emission from thermal power plants in India was estimated to be $4.98 \times 10^{8}$ metric tons in the year 2009-2010 [4]. India has about 116 coal based thermal power plants with near about 429 units.

The total power capacity from all these plants comes around 167,707.88 MW per year [5]. The impact of this huge $\mathrm{CO}_{2}$ emission is rising of global temperature, i.e. global warming, which is posing great threat not only to the environment but to human life as well [6].

Therefore, there is a need to study post combustion treatment technologies for $\mathrm{CO}_{2}$ removal. Among the existing technologies for $\mathrm{CO}_{2}$ removal, absorption is one of the most suitable technology [7]. In this paper the authors have carried out detailed theoretical investigation on reactive absorption of $\mathrm{CO}_{2}$ using Monoethanolamine (MEA) solution as the solvent. The method involved in this process is reactive absorption, i.e. the absorption of $\mathrm{CO}_{2}$ from the gaseous stream into MEA accompanied by the reaction where $\mathrm{CO}_{2}$ and MEA combine to form ester $\left(\mathrm{R}_{1} \mathrm{HCOO}^{-}\right)$and primary amine $\left(\mathrm{R}_{1} \mathrm{NH}_{3}{ }^{+}\right)$which enhances the mass transfer between the two. In order to understand the state of art in $\mathrm{CO}_{2}$ absorption, the literature survey has been carried out in presented in following section.

\section{Literature studies}

Several studies have been carried out over the years on absorption and reactive absorption of $\mathrm{CO}_{2}$ using various solvents such as Methyldiethanolamine (MDEA), MEA, ammonia, Diethanolamine (DEA), blend of MDEA and ethanolamine. Zhang and Chau-Chyun [8] used electrolyte Nonrandom Two-Liquid (NRTL) activity coefficient model to develop a rigorous and thermodynamically consistent representation for the MDEA-water- $\mathrm{CO}_{2}$ system. The model has been validated for predictions of Vapor-Liquid Equilibrium (VLE), heat capacity, and $\mathrm{CO}_{2}$ heat of absorption of the MDEA-water- $\mathrm{CO}_{2}$ system temperature range of $313 \mathrm{~K}$ to $393 \mathrm{~K}$. Liu et al. [9] studied absorption of $\mathrm{CO}_{2}$ absorption in ammonia. They concluded that ammonia could be better solvent for $\mathrm{CO}_{2}$ absorption. However, they have mentioned further experimental investigations are necessary. Lawal et al. [10] presented a study on chemical absorption of $\mathrm{CO}_{2}$ in MEA solution based dynamic modeling of the absorber and regenerated columns linked together. They concluded that the model predicts the absorber and regenerator temperature profiles and $\mathrm{CO}_{2}$ profiles very well. Molina and Bouallou [11] investigated kinetics of $\mathrm{CO}_{2}$ absorption into mixed solutions of MDEA and DEA. Their study primarily focused on to optimize the blend composition to capture $\mathrm{CO}_{2}$.

In most of these studies, a single stage $\mathrm{CO}_{2}$ absorption using thin film mass and heat transfer laws have been considered. These studied predicted the distance, from gas-liquid interface to the point at which $\mathrm{CO}_{2}$ get absorbed in the solvent, using either equilibrium stage or rate based model.

A study done using gPROMS showed rate based model gives better prediction than the equilibrium model for $\mathrm{CO}_{2}$ absorption using MEA. It also states that effect of $L / G$ ratio is more sensitive than effect of flow rate change [12] which was verified in this study as well. Another study rate based model was validated using 0.1 MW pilot plant in South Korea which showed good agreement with data except when the $L / G$ ratios taken were low [13]. Study of $\mathrm{CO}_{2}$ absorption using aq. MEA using a packed tower has been done which were in agreement with industry scale pilot plant data [14].

Dynamic modeling of $\mathrm{CO}_{2}$ absorption from coal-fired power plants into an aqueous monoethanolamine solution has been carried out using Aspen Tech software [15]. The authors have studied the transient simulation of absorption column and the results are validated with experimental data. A detailed a state-of-the-art review on post-combustion $\mathrm{CO}_{2}$ capture with chemical absorption is presented by Wang et al. [16]. The authors have concluded that more efforts in future should be directed to reduce energy combustion in 
post combustion $\mathrm{CO}_{2}$ capture with chemical absorption. Dynamic behavior of coal-fired power plants with post combustion $\mathrm{CO}_{2}$ capture is studied by Wellner et al. [17]. The authors used a model-based control strategy based on existing directives for power plants with post combustion $\mathrm{CO}_{2}$ capture. Aboudheir et al. [18], investigated the kinetics of the reaction between $\mathrm{CO}_{2}$ and high $\mathrm{CO}_{2}$-loaded, concentrated aqueous solutions of MEA for the temperature range from 293 to $333 \mathrm{~K}$. They proposed a new termolecular-kinetics model, for $\mathrm{CO}_{2}$-MEA solution, which proved to be better than previously published kinetic models. Zhang and Chen [19] have performed simulation studies with both the rigorous rate-based model and the traditional equilibrium stage model for $\mathrm{CO}_{2}$ absorption with MEA. The model results were validated with the pilot plant data from recently published literature. They concluded that the rate-based model yields better predictions compared to equilibrium stage model. Plaza et al. [20], presented results of $\mathrm{CO}_{2}$ absorption in MEA with a new model that uses a rigorous thermodynamic model from the published literatures.

From above mentioned literature survey it is noted that researchers across the globe are striving to find the unique model for prediction of the performance of absorption column for the $\mathrm{CO}_{2}$ absorption. Authors have used rate based and equilibrium NRTL models and simulated them using various software like gPROMS and ASPEN plus. Most of papers don't provide the data for overall estimations of concentration profile of $\mathrm{CO}_{2}$ (performance of the column) and its variation with $L / G$ ratio and number of stages.

In view of above, this study tried to provide the theoretical investigation of the absorption tower to predict the performance of the single stage as well as the absorption column for $\mathrm{CO}_{2}$ absorption. Further, it provides the stage concentration profiles of $\mathrm{CO}_{2}$ at various temperatures, inlet flow rates and liquid to gas ratios. The liquid phase $\mathrm{CO}_{2}$ concentration on a particular stage is estimated using interfacial mass transfer concepts and by applying Henry's law at the gas-liquid interface. Further the prediction of overall estimate of the $\mathrm{CO}_{2}$ absorption has been done using unified method. The overall objective of this study is to predict and understand the dynamics of absorption column for the removal of $\mathrm{CO}_{2}$. The outcome of the study can be used for improvements in the operations of the commercial absorption columns for $\mathrm{CO}_{2}$ absorption as well as for the designing of new column for the same.

\section{MODEL DEVELOPMENT}

$\mathrm{CO}_{2}$ containing outlet stream of desulphurization unit is the input to the absorption column. This stream consists of $\mathrm{CO}_{2}$ mixed with compounds like Sulphur dioxide $\left(\mathrm{SO}_{2}\right)$ and Nitrogen oxides $\left(\mathrm{NO}_{\mathrm{x}}\right) . \mathrm{SO}_{2}$ also has a high tendency to react with aqueous MEA solution and interfere in the $\mathrm{CO}_{2}$ absorption and therefore a desulphurization unit has to be installed before the absorption column to bring the concentration of $\mathrm{SO}_{2}$ down enough so that it wouldn't have much effect on $\mathrm{CO}_{2}$ absorption. A maximum of $10 \mathrm{ppmv}$ of $\mathrm{SO}_{2}$ concentration and less than 20 ppmv for $\mathrm{NO}_{\mathrm{x}}$ concentration [18] is acceptable for the absorption column to work efficiently.

A column with multiple trays is considered in which the treated flue gas is moved counter currently with MEA solution. The $\mathrm{CO}_{2}$ present in the flue gas reacts with the solvent in a pseudo first order kinetics where carbamate formation takes place [19]. This reaction enhances the mass transfer from gas phase to the liquid phase, thus the absorbed $\mathrm{CO}_{2}$ is separated from the flue gas as it moves upwards in the absorption column. To find the amount of $\mathrm{CO}_{2}$ which gets absorbed horizontally (on a stage) undergoing mass transfer forming a thin film between gas and liquid phase is considered under the following assumptions:

- The gas phase offers no resistance to mass transfer, the resistance offered is by the liquid film only; 
- No vaporization of solvent, since the vapor pressure of MEA is very less at the temperature rage considered for this work;

- Henry's law is applicable at the interface of the gas and liquid phase;

- Temperature is assumed to be constant throughout the complete process;

- Gas liquid equilibrium is assumed at each stage.

$\mathrm{N}$-stage equilibrium model is developed using material balance equation, equilibrium relations and summation equations as follows:

Material balance:

$$
V_{i+1}+L_{i-1}-V_{i}-L_{i}+F_{i}=0
$$

Equilibrium relation:

$$
Y_{i}=K_{i} \times X_{i}
$$

Summation equation:

$$
\Sigma Y_{i}=1 \text { and } \Sigma X_{i}=1
$$

\section{Reaction involved}

The reaction of $\mathrm{CO}_{2}$ with MEA involves the following reactions [19] into ester and amine:

$$
\begin{gathered}
\mathrm{R}_{1} \mathrm{NH}_{2}+\mathrm{CO}_{2}<-->\mathrm{H}^{+}+\mathrm{R}_{1} \mathrm{HCOO}^{-} \\
\mathrm{R}_{1} \mathrm{NH}_{2}+\mathrm{H}^{+}<-->\mathrm{R}_{1} \mathrm{NH}_{3}^{+}
\end{gathered}
$$

Overall reaction:

$$
\mathrm{CO}_{2}+2 \mathrm{R}_{1} \mathrm{NH}_{2}<-->\mathrm{R}_{1} \mathrm{HCOO}^{-}+\mathrm{R}_{1} \mathrm{NH}_{3}^{+}
$$

\section{Parameters used}

Parameters involved in this model are diffusivity of $\mathrm{CO}_{2}$ and Nitrogen dioxide $\left(\mathrm{N}_{2} \mathrm{O}\right)$ in MEA and water, Henry's constant at gas-liquid interface, density of aqueous MEA, rate and equilibrium constant of the reactions. The relations for above said parameters are provided below.

Diffusivity equation. The diffusivity coefficient of $\mathrm{CO}_{2}$ in MEA was estimated using the $\mathrm{N}_{2} \mathrm{O}$ analogy developed by $\mathrm{Ko}[20]$ :

$$
D_{\mathrm{CO}_{2} \cdot \mathrm{MEA}}=D_{\mathrm{N}_{2} \mathrm{O} \cdot \mathrm{MEA}} \times\left(D_{\mathrm{CO}_{2}} / D_{\mathrm{N}_{2} \mathrm{O}}\right)_{\text {water }}
$$

The equations of the diffusivity used were given by Versteeg and Vanswaaij [21]:

$$
\begin{gathered}
D_{\mathrm{N}_{2} \mathrm{O} . \mathrm{MEA}}=b_{0} e^{[-2,371 / r]} \\
D_{\mathrm{CO}_{2} \cdot \mathrm{MEA}}=b_{s} e^{[-2,119 / r]} \\
D_{\mathrm{N}_{2} \text { O.MEA }}=b_{0}+b_{1} C_{\text {amine }}+b_{2} C_{\text {amine }} \times e^{\left[b_{3}+b_{4} C_{\text {amine } / T]}\right.}
\end{gathered}
$$

The values of constants in diffusivityrelations are taken from Ko et al. [20], and are given in Table 1. 
Table 1. Values of constants in diffusivity relations

\begin{tabular}{lllllll}
$b_{0}=5.07 \times 10^{-6}$ & $b_{1}=8.65 \times 10^{-7}$ & $b_{2}=2.78 \times 10^{-7}$ & $b_{3}=-2,371$ & $b_{4}=-93.4$ & $b_{5}=2.35 \times 10^{-6}$ & $b_{6}=-2,119$ \\
\hline
\end{tabular}

Density relations. The density of aq. MEA solution was taken as $1,013 \mathrm{~kg} / \mathrm{m}^{3}$ using the relations from Weiland et al. [22].

Solubility relation (Henry's law). The Henry's law constant is estimated using $\mathrm{N}_{2} \mathrm{O}$ analogy by Clarke [23]:

$$
\begin{gathered}
H_{\mathrm{CO}_{2} \cdot \mathrm{MEA}}=H_{\mathrm{N}_{2} \mathrm{O} . \mathrm{MEA}} \times\left(H_{\mathrm{CO}_{2}} / H_{\mathrm{N}_{2} \mathrm{O}}\right)_{\text {water }} \\
H_{\text {gas. } \mathrm{H}_{2} \mathrm{O}}=e^{\left(a_{0}+\frac{a_{1}}{T}+a_{2} \operatorname{In} T+a_{3} T\right)}
\end{gathered}
$$

These constants are function of temperature Penttila et al. [24], and are provided in Table 2.

Table 2. Values of constants for Henry's constant relations

\begin{tabular}{ccccc}
\hline Henry's constants & $a_{0}$ & $a_{1}$ & $a_{2}$ & $a_{3}$ \\
\hline$H_{\mathrm{N}_{2} \mathrm{O}, \mathrm{H}_{2} \mathrm{O}}$ & 158.24 & $-9,048.59$ & -20.86 & -0.00252 \\
$H_{\mathrm{CO}_{2}, \mathrm{H}_{2} \mathrm{O}}$ & 145.36 & $-8,172.35$ & -19.30 & 0 \\
$H_{\mathrm{N}_{2} \mathrm{O}, \mathrm{MEA}}$ & $-9,172.5$ & 39.59 & - & - \\
\hline
\end{tabular}

Rate of reaction. There have been many discussions regarding the order of rate of reaction with respect to both $\mathrm{CO}_{2}$ and MEA. In most of literature studies, the order of reaction with respect to $\mathrm{CO}_{2}$ is assumed to be 1 but the order of reaction with respect to MEA was found to be in the range 1 to 2 . However, in most of the studies reaction rate constant has been taken as $1^{\text {st }}$ order with respect to MEA. Thus, the overall order was found to be 2 [25]. But in this study the authors have considered pure MEA with no vaporization in gas phase due to very less vapor pressure of MEA (40 pascal at $20{ }^{\circ} \mathrm{C}$ ), hence in this study a pseudo first order reaction is considered. The rate constant was found using following relation given by Aboudheir et al. [26]:

$$
k=4.61 \times 10^{9} \mathrm{e}^{(-4,412 / r)}
$$

Equilibrium constant was calculated with the help of following relation [27, 28]:

$$
\text { In } K=\mathrm{A}+\mathrm{B} / T+\mathrm{C} \times \operatorname{In} T+\mathrm{D} \times T
$$

The values of these constants are given in Table 3.

Table 3. Values of constants for equilibrium constant

\begin{tabular}{cccc}
\hline $\mathrm{A}$ & $\mathrm{B}$ & $\mathrm{C}$ & $\mathrm{D}$ \\
\hline 231.46 & $-12,092.1$ & -36.78 & 0 \\
\hline
\end{tabular}

Operational details. A pure MEA solution is supplied from top of the absorption column counter currently to the gaseous stream with $\mathrm{CO}_{2}$ as a major component. Mathematical model has been developed for this system. Simulation studies are carried out at two temperatures $298 \mathrm{~K}$ and $313 \mathrm{~K}$, with $\mathrm{CO}_{2}$ compositions of 0.6 and 0.8 to find 
$\mathrm{CO}_{2}$ concentration profile across the gas-liquid interface at a given stage. Simulation studies are further carried out to estimate overall absorption of $\mathrm{CO}_{2}$ in absorption column, at different inlet flow rates of $\mathrm{CO}_{2}: 65.74,75.74,85.74$ and $95.74 \mathrm{kmol} / \mathrm{m}^{3}$, at different $L / G$ ratios: $2,6.5,8.5$ and at different number of stages 15,25 and 30 .

\section{Development of model using unified method}

In this method, $N$ numbers of stages are considered for absorption of $\mathrm{CO}_{2}$ using MEA as the solvent. Flue gas and MEA are flowing counter currently in the tower where the flue gas is fed from the bottom most tray $\left(V_{\mathrm{n}}\right)$, where as pure MEA is added from the top tray. At each tray, fractional amount of $\mathrm{CO}_{2}$ gets absorbed into MEA and flue gas which is now $\mathrm{CO}_{2}$ lean moves to the next upper plate. The process continues up to the $N^{\text {th }}$ stage, post which the lean flue gas moves into the stack for removal. The schematic of $i^{\text {th }}$ stage is shown in Figure 1.

The overall mass balance equation gives:

$$
V_{i+1}+L_{i-1}-V_{i}-L_{i}+F_{i}=0
$$

The component balance gives:

$$
\left(Y_{I+1} V_{i+1}\right)+\left(X_{i-1} L_{i-1}\right)-\left(Y_{i} V_{i}+X_{i} L_{i}\right)+F_{i}=0
$$

where $V_{i}$ decreases by $N_{\mathrm{a}} A V_{\mathrm{m}}$ amount at each stage because of $\mathrm{CO}_{2}$ absorption and its reaction with monoethanolamine.

Equilibrium relation:

$$
Y_{i}=K_{i} \times X_{i}
$$

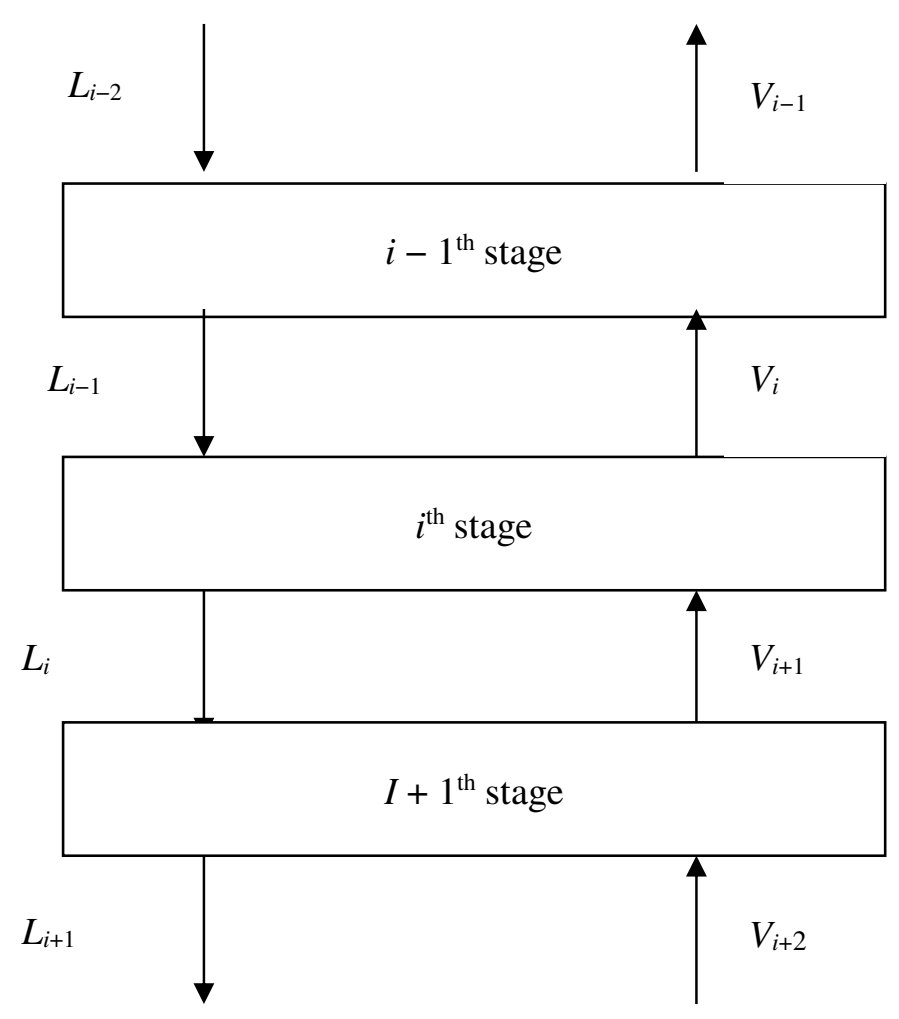

Figure 1. $N$-stage equilibrium model

The process depends on the stripping factor $\left(S_{i}\right),\left(V_{i} K_{i}\right) / L_{i}$, which makes the equation: 


$$
Y_{i+1, j} V_{i+1, j}+y_{i, j} V_{i, j}\left[\left(L_{i, j} / G_{i, j} K_{i, j}\right)-1\right]+y_{i-1, j} V_{i-1, j}\left[\left(L_{i, j} / G_{i, j} K_{i, j}\right)\right]+F_{i}=0
$$

or:

$$
Y_{i+1, j} V_{i+1, j}+y_{i, j} V_{i, j}\left[\left(1 / S_{i, j} K_{i, j}\right)-1\right]+y_{i-1, j} V_{i-1, j}\left[\left(1 / S_{i, j} K_{i, j}\right)\right]+F_{i}=0
$$

where $S_{i, j}$ is the stripping factor, i.e:

$$
S_{i, j}=\left(G_{i, j} \times K_{i, j}\right) / L_{i, j}
$$

Solution procedure. The model equations are solved using the equilibrium matrix method (Thomas algorithm) to estimate overall absorption $\mathrm{CO}_{2}$ in the tower. It is simplification of Gaussian elimination method which is used to solve system of equations, using forward and backward substitutions. For this purpose the MATLAB software has been used. The $K$ value in the equilibrium relation is calculated using the Henry's constant at the interface of the two medium.

\section{RESULTS AND DISCUSSION}

The simulation studies for the absorption column were carried outto find the mole fraction of $\mathrm{CO}_{2}$ absorbed at each stage. The overall absorption of $\mathrm{CO}_{2}$ in absorption column is also estimated.

\section{Parameters values}

The parameters values used, at two temperatures $298 \mathrm{~K}$ and $318 \mathrm{~K}$, in simulation studies are mentioned in Table 4. The parameters viz., rate constant, Henry's constant, diffusion coefficient of $\mathrm{CO}_{2}$ and MEA are used for this study.

Table 4. Effect of variation of temperature on different parameters

\begin{tabular}{cll}
\hline Parameters & \multicolumn{1}{c}{$T=298 \mathrm{~K}$} & $T=318 \mathrm{~K}$ \\
\hline Rate constant $\left[\mathrm{s}^{-1}\right]$ & $1.713211 \times 10^{3}$ & $4.34716 \times 10^{3}$ \\
Henry's constant $\left[\mathrm{kPa} \mathrm{m}^{3} / \mathrm{kmol}\right]$ & $2.162313 \times 10^{8}$ & $2.927188 \times 10^{8}$ \\
Diffusion coefficient of $\mathrm{CO}_{2}\left[\mathrm{~m}^{2} / \mathrm{s}\right]$ & $1.293194 \times 10^{-9}$ & $2.2309 \times 10^{-9}$ \\
Diffusion coefficient of ${\mathrm{MEA}\left[\mathrm{m}^{2} / \mathrm{s}\right]}^{7.280607 \times 10^{-10}}$ & $1.15787 \times 10^{-9}$ \\
\hline
\end{tabular}

Variation of rate constant with temperature. As the temperature increases the rate constant also increases which in turn enhances the reaction rate of $\mathrm{CO}_{2}$ with MEA solution and thus increases absorption.

Variation of Henry's constant with temperature. The value of Henry's constant increases at the interface of gas and liquid with increase in temperature.

Variation of diffusion coefficient with temperature. Diffusion coefficients also increase with temperature and hence increase the diffusion of the acidic gas into the liquid solution.

\section{Stage-wise variation in concentration profile}

The effect of change in the inlet gas temperature and inlet $\mathrm{CO}_{2}$ composition, on the concentration profile of $\mathrm{CO}_{2}$ from the gas-liquid interphase to bulk MEA at a given stage is presented in Figure 2 and Figure 3, respectively. These studies were carried out at constant inlet $\mathrm{CO}_{2}$ flow rate of $75.74 \mathrm{kmol} / \mathrm{m}^{3}$ and $L / G$ ratio of 8.5 . 


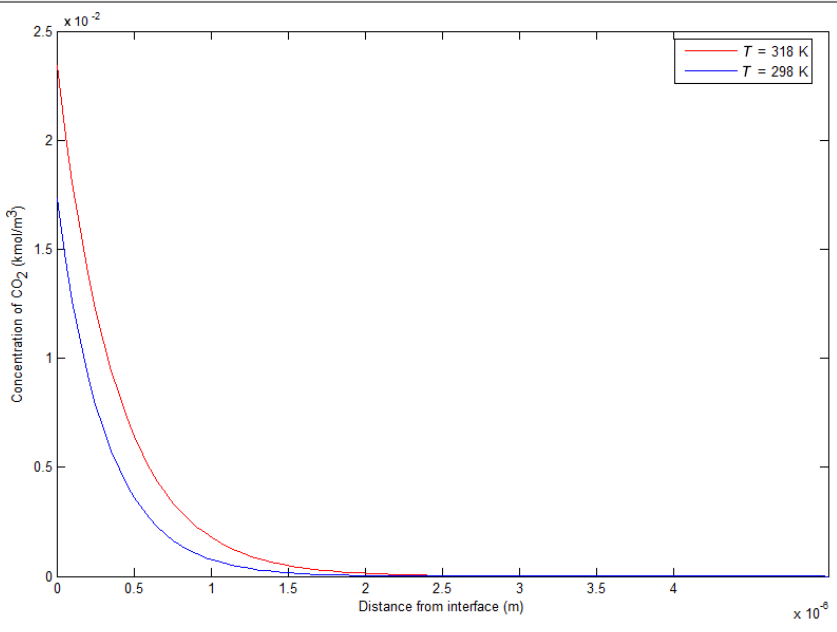

Figure 2. Effect of change in temperature on $\mathrm{CO}_{2}$ concentration profile

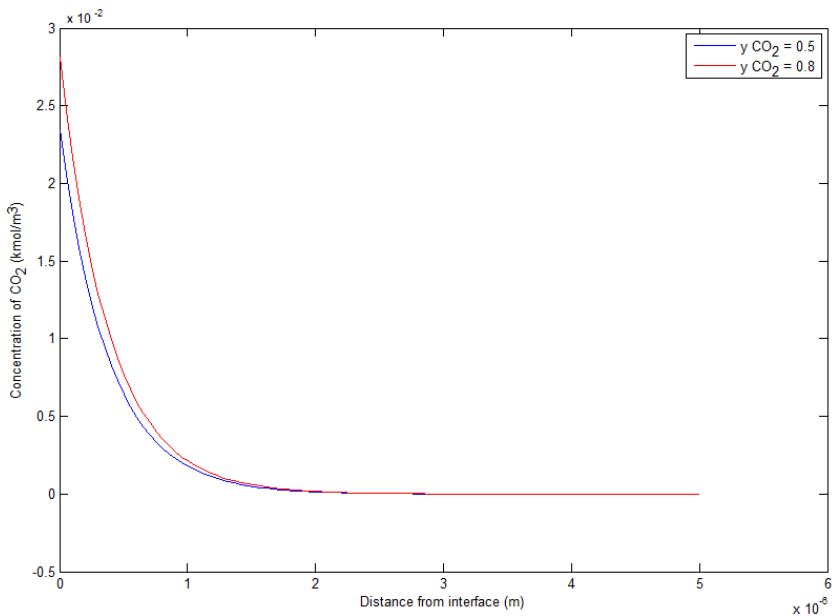

Figure 3. Effect of change in inlet $\mathrm{CO}_{2}$ composition on $\mathrm{CO}_{2}$ concentration profile

Effect of temperature on concentration profile $\left(y_{\mathrm{CO}_{2}}=0.8\right)$. Figure 2 presents the effect of temperature on $\mathrm{CO}_{2}$ profile from gas-liquid interphase to bulk liquid phase. From Figure 2 it is noted that $2.35 \times 10^{-2} \mathrm{kmol} / \mathrm{m}^{3}$ of $\mathrm{CO}_{2}$ gets absorbed completely into the aqueous MEA solution at a distance of $2.1 \times 10^{-6} \mathrm{~m}$ from gas-liquid interface at temperature $318 \mathrm{~K}$. However, at $298 \mathrm{~K}, 1.76 \times 10^{-2} \mathrm{kmol} / \mathrm{m}^{3}$ of $\mathrm{CO}_{2}$ gets absorbed completely into the aq. MEA solution at a distance of $1.5 \times 10^{-6} \mathrm{~m}$ from the gas-liquid interface.

Thus, from above results it is noted that with increase in temperature the concentration of $\mathrm{CO}_{2}$ increases at the interface which gets absorbed within film thickness. This is due to the fact that with increase in temperature, the solubility of the acidic gas increases in the solvent. Hence, using the thin film layer model, $\mathrm{CO}_{2}$ concentration was found to decrease from interface concentration at equilibrium to a minimum of $0 \mathrm{kmol} / \mathrm{m}^{3}$ up to a distance within \pm 2 micrometers.

Effect of inlet $\mathrm{CO}_{2}$ composition on concentration profile $(T=318 \mathrm{~K})$. The Figure 3 shows effect of change in inlet $\mathrm{CO}_{2}$ composition on $\mathrm{CO}_{2}$ profile from gas-liquid interphase to bulk liquid phase. From Figure 3 it is observed that as the inlet $\mathrm{CO}_{2}$ composition in the flue gas is increased from 0.5 to 0.8 the interface concentration of $\mathrm{CO}_{2}$ also increased from $2.35 \times 10^{-2} \mathrm{kmol} / \mathrm{m}^{3}$ to $2.75 \times 10^{-2} \mathrm{kmol} / \mathrm{m}^{3}$ at that particular stage. However, there is no change in the distance from gas-liquid interface for $\mathrm{CO}_{2}$ concentration to reduce to zero. 


\section{Overall estimate}

The overall estimate of $\mathrm{CO}_{2}$ absorption in absorption column has been carried out using unified method. Here at each stage, it is considered that a constant amount $\left(N_{\mathrm{a}} \times A \times V_{\mathrm{m}}\right)$ of $\mathrm{CO}_{2}$ is getting absorbed due to the reaction of $\mathrm{CO}_{2}$ with MEA solvent. Where $N_{\mathrm{a}}$ is the molar flow rate, $A$ is area and $V_{\mathrm{m}}$ is the molar volume at that temperature. The film area is taken as $2.5 \mathrm{~m} \times 0.4 \mathrm{~m}$ and molar volume is taken as $24.86 \mathrm{~m}^{3} / \mathrm{kmol}$ using gas law at $318 \mathrm{~K}$. The major component of inlet flue gas is considered to be $\mathrm{CO}_{2}$ as the outlet from the desulphurization unit is rich in $\mathrm{CO}_{2}$ concentration because most of the $\mathrm{SO}_{2}$ content is removed in the desulfurization unit.

The overall percentage of $\mathrm{CO}_{2}$ absorption is calculated by subtracting outlet mole fraction at stage 1 at the top from inlet mole fraction at the bottom and dividing it by inlet mole fraction.

Effect of change in $L / G$ on overall $\mathrm{CO}_{2}$ absorption. Figure 4 present the effect of change in $L / G$ on overall $\mathrm{CO}_{2}$ absorption. The simulation studies are carried out at inlet $\mathrm{CO}_{2}$ composition of varying in the range from 0.85 to 0.95 , inlet $\mathrm{CO}_{2}$ flow rate of $75.74 \mathrm{kmol} / \mathrm{m}^{3}$, temperature of $318 \mathrm{~K}$ and with 30 numbers of theoretical stages. The details of input/output streams composition along with $L / G$ ratio is provided in Table 5. From the figure it is observed that overall $\mathrm{CO}_{2}$ absorption increases from $66.73 \%$ to $95.60 \%$ with increase in $L / G$ ratio from 2 to 8.5 , respectively. This must be attributed to fact that the increase in solvent rate enhances the absorption rate. It is also seen from the Figure 4 that for $L / G$ ratio $8.5, \mathrm{CO}_{2}$ profile across the column is almost flat as compared to $\mathrm{CO}_{2}$ profile at $L / G$ ratio 2 and 4.5 .

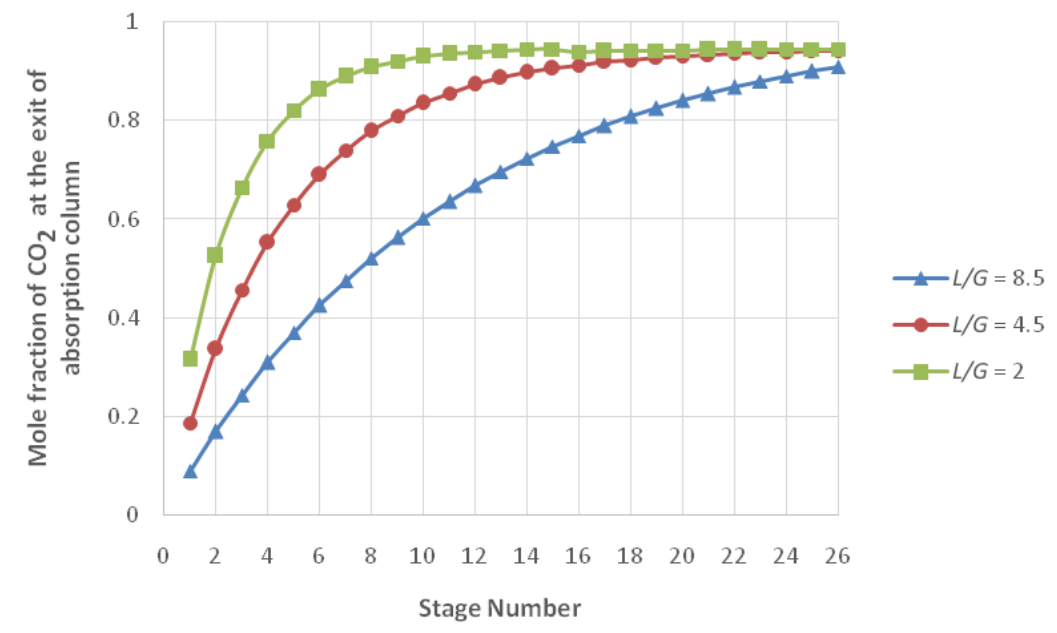

Figure 4. Effect of change in $L / G$ on overall $\mathrm{CO}_{2}$ absorption

Table 5. Input-output streams data

\begin{tabular}{cccc}
\hline Sr No. & $L / G$ ratio & Inlet $\mathrm{CO}_{2}$ composition & Outlet $\mathrm{CO}_{2}$ composition \\
\hline 1 & 2 & 0.95 & 0.31 \\
2 & 4.5 & 0.95 & 0.185 \\
3 & 8.5 & 0.92 & 0.039 \\
\hline
\end{tabular}

Effect of change in no of stages on overall $\mathrm{CO}_{2}$ absorption. The effect of change in no of stages on overall $\mathrm{CO}_{2}$ absorption is presented in Figure 5. The simulation studies are carried out at constant inlet $\mathrm{CO}_{2}$ composition of 0.8 , inlet $\mathrm{CO}_{2}$ flow rate of $75.74 \mathrm{kmol} / \mathrm{m}^{3}$, temperature of $318 \mathrm{~K}$ and with $L / G$ ratio of 8.5 . It can be noted from Figure 5 that overall $\mathrm{CO}_{2}$ absorption increases as the number of stages are increased from 15 to 30 . 


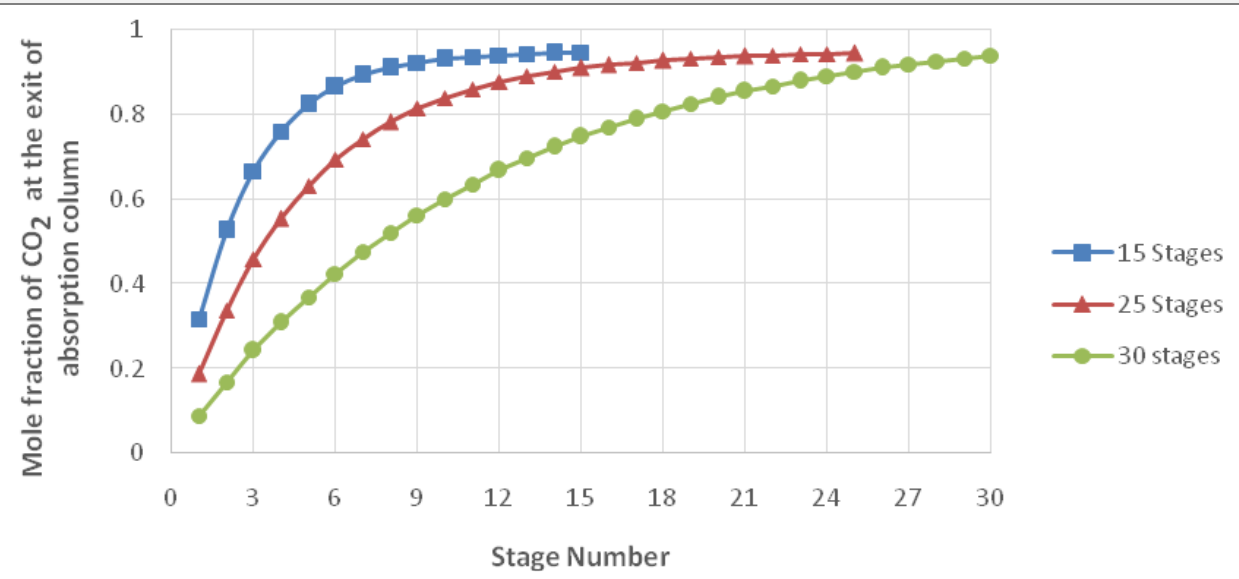

Figure 5. Effect of change in no of stages on overall $\mathrm{CO}_{2}$ absorption

Effect of change in inlet $\mathrm{CO}_{2}$ flow rates on overall $\mathrm{CO}_{2}$ absorption. Figure 6 presents effect of change in inlet $\mathrm{CO}_{2}$ flow rate on overall $\mathrm{CO}_{2}$ absorption. The simulation studies are carried out at constant inlet $\mathrm{CO}_{2}$ composition of 0.8 , temperature of $318 \mathrm{~K}$, number of stages as 30 and with $L / G$ ratio of 8.5. It can be seen from the figure that as the flow rate increases the absorption rate also increases but the change is very gradual. The absorption is the minimum for $65.74 \mathrm{kmol} / \mathrm{hr}$ and maximum for $95.74 \mathrm{kmol} / \mathrm{hr}$. This is because as the inlet $\mathrm{CO}_{2}$ flow rate increases, the interface $\mathrm{CO}_{2}$ concentration increases and hence absorption of $\mathrm{CO}_{2}$ into MEA increases.

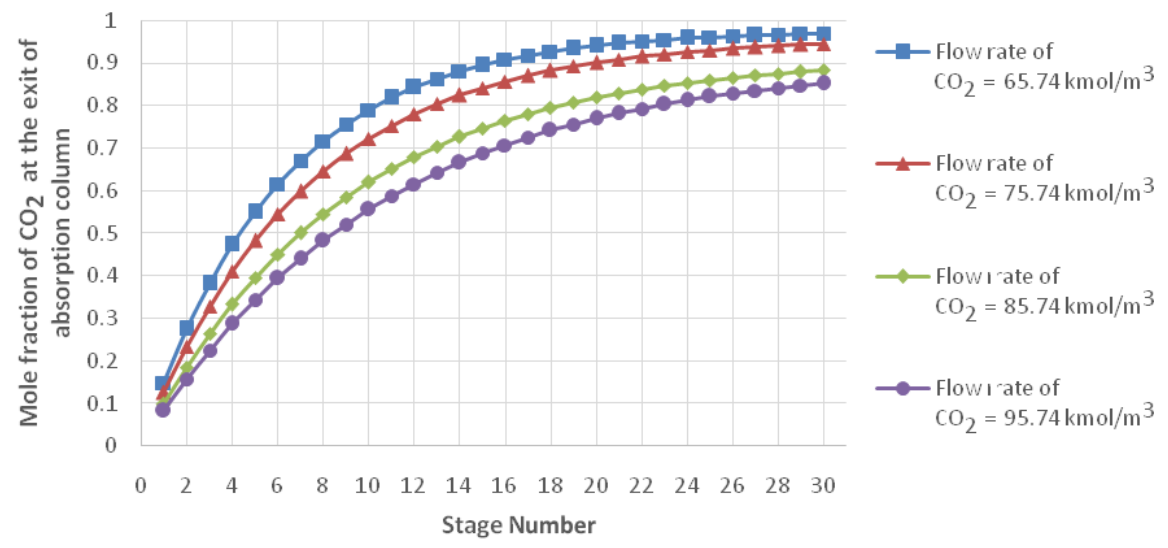

Figure 6. Effect of change in inlet $\mathrm{CO}_{2}$ flow rates on overall $\mathrm{CO}_{2}$ absorption

\section{CONCLUSIONS}

The expansion of economy and population with current technology leads to higher rates of urbanization, industrialization and deforestation, all factors contributing to an increase in $\mathrm{CO}_{2}$ level in the surrounding. So, steps need to be taken in order to reduce this level wherein the first step that has to be taken would be to trap the industrial $\mathrm{CO}_{2}$ emissions in the most efficient and economical way. This can be achieved by post combustion capture of $\mathrm{CO}_{2}$ using absorption columns.

The film model gives an overview as to how the $\mathrm{CO}_{2}$ absorption takes place for a particular tray and the thickness up to which entireamount of $\mathrm{CO}_{2}$ gets absorbed. From the stage wise $\mathrm{CO}_{2}$ concentration profile it is noted that the absorption of $\mathrm{CO}_{2}$ into MEA is very instantaneous. This may be attributed to the fact that reactive absorption is very effective in $\mathrm{CO}_{2}$ absorption. This study also gives us visualization as to how absorption takes place at each tray throughout the column. This study has revealed the important design variables which controls the overall absorption of $\mathrm{CO}_{2}$. 
The unified model approach is best suited for overall estimation of $\mathrm{CO}_{2}$ absorption. From the results it is noted that, $95.60 \%$ of the inlet $\mathrm{CO}_{2}$ can be absorbed in absorption column with 30 trays, $L / G$ ratio of 8.5 and inlet $\mathrm{CO}_{2}$ flow rate of $95.74 \mathrm{kmol} / \mathrm{m}^{3}$. From the results it is also noted that $\mathrm{CO}_{2}$ absorption in the tower is more sensitive to $L / G$ ratio as compared to composition or flow rate changes which is in accordance with literature studies.

\section{NOMENCLATURE}

$\begin{array}{llc}A & \text { film area } & {\left[\mathrm{m}^{2}\right]} \\ D_{\mathrm{CO}_{2}} & \text { diffusion coefficient of } \mathrm{CO}_{2} & {\left[\mathrm{~m}^{2} / \mathrm{s}\right]} \\ D_{\mathrm{MEA}} & \text { diffusion coefficient of monoethanolamine } & {\left[\mathrm{m}^{2} / \mathrm{s}\right]} \\ F_{i} & \text { feed stage } & {[-]} \\ H_{\mathrm{CO}_{2}} & \text { Henry's constant } & {[\mathrm{kPa} \mathrm{m} / \mathrm{kmol}]} \\ k & \text { rate constant } & {\left[\mathrm{sec}^{-1}\right]} \\ K & \text { equilibrium constant } & {[-]} \\ L & \text { liquid flow rate } & {\left[\mathrm{m}^{3} / \mathrm{sec}\right]} \\ N_{\mathrm{a}} & \text { mass flux } & {\left[\mathrm{kmol}^{2} / \mathrm{m}^{2} \mathrm{~s}\right]} \\ S_{i, j} & \text { stripping factor } & {[-]} \\ V & \text { vapor flow rate } & {\left[\mathrm{m}^{3} / \mathrm{sec}\right]} \\ V_{\mathrm{m}} & \text { molar volume } & {\left[\mathrm{m}^{3} / \mathrm{kmol}^{3}\right]} \\ X & \text { liquid mole fraction } & {[-]} \\ Y & \text { vapor mole fraction } & {[-]}\end{array}$

\section{Subscripts}

$i$

stage

j component

\section{REFERENCES}

1. Netherlands Environmental Assessment Agency, $\mathrm{CO}_{2}$ Time Series 1990-2014 per Region/country, http://edgar.jrc.ec.europa.eu/overview.php?v=CO2ts1990-2014, [Accessed: 30-November-2015]

2. Shilpa Kumari, Rao, P. S., Electricity from Nuclear Power: Is it a Solution to Greenhouse Gas Emissions In India, International Journal of Scientific \& Technology Research, Vol. 2, No. 12, pp 242-247, 2013.

3. Central Electricity Authority, Ministry of Power, Government of India, Broad Status of Thermal Power Projects, $p$ 23, http://www.cea.nic.in/reports/monthly/broadstatus/2015/broad_status-12.pdf, 2015, [Accessed: 01-October-2015]

4. Mittal, Moti, L., Chhemendra Sharma and Richa Singh, Estimates of emissions from Coal fired Thermal Power Plants in India, International Emission Inventory Conference, pp 13-16, Florida, USA, 2012.

5. Central Electricity Authority, Executive Summary of Power Sector as on 31-03-2016, Govt. of India, New India, http://www.cea.nic.in/reports/monthly/executivesummary/2016/exe_summary-03.pdf, 2016, [Accessed: 23-May-2016]

6. Intergovernmental Panel on Climate Change, Report on Climate change, https://www.ipcc.ch/pdf/assessmentreport/ar4/wg3/ar4_wg3_full_report.pdf, [Accessed: 13-June-2018]

7. Cheng-Hsiu, Y., Huang, C.-H. and Tan, C.-S., A review of $\mathrm{CO}_{2}$ capture by absorption and adsorption, Aerosol Air Qual. Res., Vol. 12, No. 5, pp 745-769, 2012, https://doi.org/10.4209/aaqr.2012.05.0132 
8. Ying, Z. and Chen, C.-C., Thermodynamic modeling for $\mathrm{CO}_{2}$ absorption in aqueous MDEA Solution with Electrolyte NRTL Model, Industrial\&Engineering Chemistry Research, Vol. 50, No. 1, pp 163-175, 2010, https://doi.org/10.1021/ie1006855

9. Liu, J., Wang, S., Zhao, B., Tong, H., Chen, C., Absorption of Carbon Dioxide in Aqueous Ammonia, Energy Procedia, Vol. 1, No. 1, pp 933-940, 2009, https://doi.org/10.1016/j.egypro.2009.01.124

10. Lawal, A., Wang, M., Stephenson, P., Koumpouras, G., Yeung, H., Dynamic modelling and analysis of post combustion $\mathrm{CO}_{2}$ chemical absorption Process for Coal-fired Power Plants, Fuel, Vol. 89, No. 10, pp 2791-2801, 2010, https://doi.org/10.1016/j.fuel.2010.05.030

11. Toro-Molina, C. and Bouallou, C., Kinetics Study and simulation of $\mathrm{CO}_{2}$ absorption into mixed aqueous Solutions of Methyldiethanolamine and Diethanolamine, Chemical Engineering Transactions, Vol. 35, pp 319-324, 2013.

12. Lawal, A., Wang, M., Stephenson, P. and Yeung, H., Dynamic modelling of $\mathrm{CO}_{2}$ absorption for post combustion capture in Coal-fired Power Plants, Fuel, Vol. 88, No. 12, pp 2455-2462, 2009, https://doi.org/10.1016/j.fuel.2008.11.009

13. Lim, Y., Kim, J., Jung, J., Chi Seob Lee, and Han, C., Modeling and simulation of $\mathrm{CO}_{2}$ capture Process for Coal-based Power Plant using Amine Solvent in South Korea, Energy Procedia, Vol. 37, pp 1855-1862, 2013, https://doi.org/10.1016/j.egypro.2013.06.065

14. Khan, F. M., Krishnamoorthi, V. and Mahmud, T., Modelling reactive absorption of $\mathrm{CO}_{2}$ in packed Columns for post-combustion Carbon capture Applications, Chemical Engineering Research and Design, Vol. 89, No. 9, pp 1600-1608, 2011, https://doi.org/10.1016/j.cherd.2010.09.020

15. Posch, S. and Haider, M., Dynamic modeling of $\mathrm{CO}_{2}$ absorption from Coal-fired Power Plants into an aqueous Monoethanolamine Solution, Chemical Engineering Research and Design, Vol. 91, No. 6, pp 977-987, 2013, https://doi.org/10.1016/j.cherd.2012.09.016

16. Wang, M., Lawal, A., Stephenson, P., Sidders, J. and Ramshaw, C., Post-combustion $\mathrm{CO}_{2}$ capture with Chemical absorption: A State-of-the-art review, Chemical Engineering Research and Design, Vol. 89, No. 9, pp 1609-1624, 2011, https://doi.org/10.1016/j.cherd.2010.11.005

17. Wellner, K., Marx-Schubach, T. and Schmitz, G., Dynamic behavior of Coal-fired Power Plants with post combustion $\mathrm{CO}_{2}$ capture, Ind. Eng. Chem. Res., Vol. 55, No. 46, pp 12038-12045, 2016, https://doi.org/10.1021/acs.iecr.6b02752

18. Aboudheir, A., Tontiwachwuthikul, P., Chakma, A. and Idem, R., Kinetics of the reactive absorption of Carbon Dioxide in high $\mathrm{CO}_{2}$-loaded, concentrated aqueous Monoethanolamine Solutions, Chemical Engineering Science, Vol. 58, No. 23-24, pp 5195-5210, 2013, https://doi.org/10.1016/j.ces.2003.08.014

19. Zhang, Y. and Chen, C.-C., Modeling $\mathrm{CO}_{2}$ absorption and desorption by aqueous Monoethanolamine Solution with Aspen rate-based Model, Energy Procedia, Vol. 37, pp 1584-1596, 2013, https://doi.org/10.1016/j.egypro.2013.06.034

20. Plaza, J. M., Van Wagener, D. and Rochelle, G. T., Modeling $\mathrm{CO}_{2}$ capture with aqueous Monoethanolamine, Energy Procedia, Vol. 1, pp 1171-1178, 2009, https://doi.org/10.1016/j.egypro.2009.01.154

21. Kothandaraman, A., Carbon Dioxide capture by chemical absorption: A Solvent comparison Study, M.Sc. Thesis, Massachusetts Institute of Technology, Massachusetts, USA, 2010.

22. Liu, X., Rate based modelling of $\mathrm{CO}_{2}$ removal using Alkanolamines, M.Sc. Thesis, Norwegian University of Science and Technology, Trondheim, Norway, 2014.

23. Ko, J.-J., Tsai, T.-C., Lin, C.-Y., Wang, H.-M. and Li, M.-H., Diffusivity of Nitrous Oxide in aqueous Alkanolamine Solutions, Journal of Chemical and Engineering Data, Vol. 46, No. 1, pp 160-165, 2001, https://doi.org/10.1021/je000138x 
24. Versteeg, G. F. and Vanswaaij, W. P. M., Solubility and diffusivity of Acid Gases $\left(\mathrm{CO}_{2}, \mathrm{~N}_{2} \mathrm{O}\right)$ in aqueous Alkanolamine Solutions, Journal of Chemical and Engineering Data, Vol. 33, No. 1, pp 29-34, 1988, https://doi.org/10.1021/je00051a011

25. Weiland, R. H., Dingman, J. C., Benjamin Cronin, D. and Browning, G. J., Density and Viscosity of some partially carbonated aqueous Alkanolamine Solutions and their blends, Journal of Chemical and Engineering Data, Vol. 43, No. 3, pp 378-382, 1998, https://doi.org/10.1021/je9702044

26. Clarke, J. K. A., Kinetics of absorption of Carbon Dioxide in Monoethanolamine Solutions at short contact times, Industrial\&Engineering Chemistry Fundamentals, Vol. 3, No. 3, pp 239-245, 1964, https://doi.org/10.1021/i160011a012

27. Penttilä, A., Dell'Era, C., Uusi-Kyyny, P. and Alopaeus, V., The Henry's Law constant of $\mathrm{N}_{2} \mathrm{O}$ and $\mathrm{CO}_{2}$ in aqueous Binary and Ternary Amine Solutions (MEA, DEA, DIPA, MDEA, and AMP), Fluid Phase Equilibria, Vol. 311, pp 59-66, 2011, https://doi.org/10.1016/j.fluid.2011.08.019

28. Mahajani, V. V. and Joshi, J. B., Kinetics of Reactions between Carbon Dioxide and Alkanolamines, Gas Separation \& Purification, Vol. 2, No. 2, pp 50-64, 1988, https://doi.org/10.1016/0950-4214(88)80013-6

29. Aboudheir, A., Kinetics of the reactive absorption of Carbon Dioxide in high $\mathrm{CO}_{2}$-loaded, concentrated aqueous Monoethanolamine Solutions, Chemical Engineering Science, Vol. 58, No. 23-24, pp 5195-5210, 2003, https://doi.org/10.1016/j.ces.2003.08.014

30. Kothandaraman, A., Carbon Dioxide capture by chemical absorption: A Solvent comparison Study, M.Sc. Thesis, Massachusetts Institute of Technology, Massachusetts, USA, 2010.

31. Yunda, L., Zhang, L. and Watanasiri, S., Representing Vapor- liquid Equilibrium for an aqueous MEA-CO $\mathrm{CO}_{2}$ System using the Electrolyte Nonrandom-two-liquid Model, Industrial\&Engineering Chemistry Research, Vol. 38, No. 5, pp 2080-2090, 1999, https://doi.org/10.1021/ie980600v 